\title{
Case Study of Construction Cost Estimation in China Electric Power Industry Based on BIM Technology
}

\author{
Rui $\mathrm{Liu}^{1}$ and Xiaoqiang $\mathrm{Hu}^{2}$ \\ School of Economic and Management, North China Electric Power University, \\ Beijing, China \\ ${ }^{1}$ liurui@ncepu.edu.cn, ${ }^{2}$ pdrs00@163.com
}

\begin{abstract}
Building Information Modeling (BIM) is mainly being promoted and applied in civil and public building cost management, but it is seldom used in power construction industry. Electric power construction project involves many professionals and different types of buildings and structures. Coupled with Chinese specialized quantity calculation rules, these factors led to some obstacles encountered when it comes to the application of BIM. In this paper, a substation is used as the object of the study, Revit software is used to explore 5D modeling method and other problems related to cost. Especially, quantity statistics according to 2013 edition's power quota rules is the most difficult, three solutions were provided and one particularly detailed. It can be concluded that as long as it achieves data transfer, BIM 5D technology can be used in the power construction industry and it will bring huge impact on power engineering cost.
\end{abstract}

Keywords: BIM, Cost estimation, Electric power construction

\section{Introduction}

Building Information Modeling or known as BIM was proposed by Charles Eastman. BIM technology has many characteristics such as visualization, coordination, simulation and optimization. It can also carry out virtual construction and information integration with powerful computation and cooperation ability. By establishing information modeling on the early stage, it can not only be applied to design and construction stage, but also has a dramatic effect on property, operation and demolition stages. With that, we can say that the Building Information Modeling works for entire project life cycle [1].

In recent years, china electric power industry is growing fast, every year the construction investment has come to RMB 630 billion. In order to reduce cost and enhance efficiency, the authorities specifically pointed out to accelerate BIM technology application in the engineering in the 12th five-year plan [1]. As the power engineering cost has strong professional and uniqueness (see Figure 1), the tedious calculation rules and complex professional system bring a lot of problems that general engineering cost software can't solve [3]. How to use BIM 5D model to get quantity automatically according to 2013 edition's power quota rules is a difficult problem that no one has ever studied. 


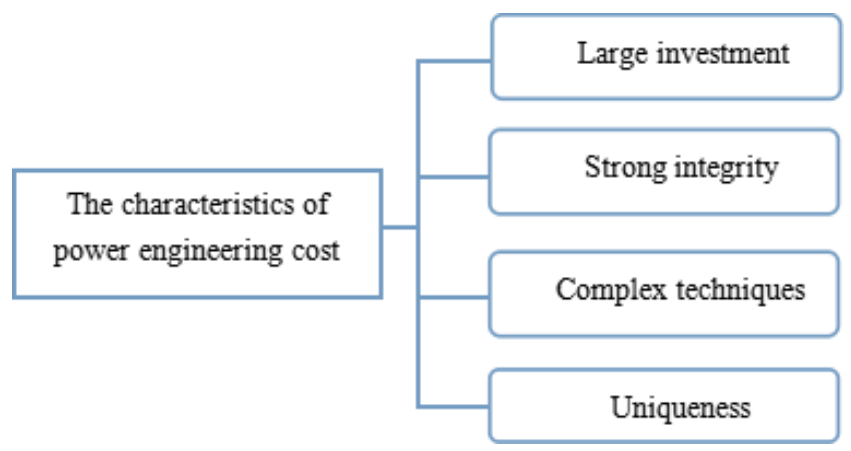

Figure 1. The Characteristics of Power Engineering Cost

Power engineering includes power source engineering and power grid engineering that contains transmission, transformation, distribution and utilization engineering. Different power engineering have different purposes, methods and equipment, and they are very complex. Such as transformer, different types, levels and manufactures lead the model quite different [4]. The main structure of substation is similar to civil building's, and the power components are relatively complete. So, the substation project, as representative of power grid engineering, is suitable as a typical case to study.

In this paper, for validate the feasibility of apply BIM 5D technology in power construction industry, three steps are used to finish the work. First, using Revit software to create family library and substation model; then get the quantity data and send it to other software to achieve data transfer; finally, match quantity with quota to realize construction cost estimation.

\section{Literature Review}

BIM model contains rich component information and has object-oriented design feature. With the help of computer data processing function, the model can recognize and mark component's geometry information, attribute information and material information, and through the statistics, processing and operation, it can realize the calculation of project cost.

In china, BIM technology applied in cost management is also called 5D BIM application. China and developed countries have different cost management system, and different regions and sectors have different quota database. Therefore, we can't directly use BIM cost software in Chinese cost industry. Besides, there are a variety of cost software on the market, such as Glodon software, Luban software and PKPM software. How to link up these cost software and BIM modeling software becomes one of pop research problems.

Cong Qi (2008) proposed the development pattern of budget software based on BIM and drew a concrete implementation plan [5]. Zhe Lou (2009) built demand information model and budget information model based on IFC standard. The platform model is divided into two parts, including BIM data core and user interface, which correspond to data exchange layer, data storage layer, data application layer and user interface layer [6]. Zhiliang Ma (2010) analyzed the domestic demand for budget software and the usability of foreign budget software, and offered research framework on the next generation of budget software [7]. Xiude Zhang (2011) used a number of software development technologies, and adopted relational database management system to finished the design and realization of the budget software system, then combined with project IFC data to demonstrated the application of this system [8].

Shujie Zhang (2012) borrowed the efficiency of BIM technology in data storage and transfer, analyzed its great application value in cost management and put forward some improving suggestions on BIM function problem [9]. Jing Li (2012) discussed BIM 
application value in the decision, design, bid and other stages' cost determination and control, and studied the cost management of total life cycle based on BIM platform [10]. Ying Wang (2012) created a cost information system that BIM as core technology and C/S $+\mathrm{B} / \mathrm{S}$ as network architecture, and determined each module's function in the system [11]. Xinwei Chai (2013) built the dynamic cost information database system and offered implementation process and solutions about engineering cost based on BIM [12].

These researchers have studied cost management based on BIM technology, but their focus vary. Qi and others tried to develop budget software based on BIM platform; Zhang et. al., Have explored BIM value in the cost management.

In developed countries, BIM utilization ratio was up to $40 \%$ and the application of BIM technology centered on process management, such as construction simulation, schedule simulation and project evaluation. Academics' findings see Table 1.

Table 1. Search Findings About BIM Technology

\begin{tabular}{|c|c|c|}
\hline Time & Scholar & Major achievement \\
\hline 2002 & Jerry Laiserin & First put forward BIM complete concept [13] \\
\hline 2003 & K Lee, S Chin, J Kim & Built DIMS information management system [14] \\
\hline 2003 & Sherl, Fischer & Developed the prototype system of engineering budget [15] \\
\hline 2005 & Vineer R. Kamat & Succeed converts BIM model to VRML format [16] \\
\hline 2005 & Ali Murat Tanyer & $\begin{array}{l}\text { Built 4D BIM system and combined it with cost estimation } \\
\text { [17] }\end{array}$ \\
\hline 2006 & Bazjanacz & $\begin{array}{c}\text { Achieved share data and work together in the entire project } \\
\text { management [18] }\end{array}$ \\
\hline 2008 & Sheryl, Alan, Ngoc & $\begin{array}{c}\text { Associated Repcon program with BIM model and realized } \\
\text { schedule stimulation [19] }\end{array}$ \\
\hline 2009 & Succar & $\begin{array}{l}\text { Emphasized BIM study should be concentrated in the } \\
\text { construction of digitization and standardization [20] }\end{array}$ \\
\hline 2009 & Kim & $\begin{array}{l}\text { Used BIM technology to run simulations of ground and } \\
\text { analyzed steel structure management [21] }\end{array}$ \\
\hline 2011 & Lachmi Khemlani & Compared and studied BIM software performance [22] \\
\hline 2012 & Ghang Lee & $\begin{array}{l}\text { Analyzed potential losses caused by BIM's defects and } \\
\text { reflected BIM's financial benefits through ROI [23] }\end{array}$ \\
\hline 2013 & David Bryde & $\begin{array}{c}\text { Demonstrated the advantage of BIM technology by } 35 \\
\text { engineering examples and } 9 \text { indicators [24] }\end{array}$ \\
\hline
\end{tabular}

In the engineering cost, especially quantity statistics, domestic results are apparently more than foreign results. But both at home and abroad, the research of BIM application in the cost management is mainly focused on civil building, and there is lack of power construction cost estimation study.

Due to huge investment, sophisticated technology and strict quality requirement, each power project is highly concerned by the local government and relevant communities. Thus, BIM technology application is now imminent in order to improve the level of power engineering cost management.

\section{Research Approach}

In this paper, a substation project as an example, applying BIM technology from family library construction to valuation and trying to accomplish power engineering cost. The research framework see Figure 2. 


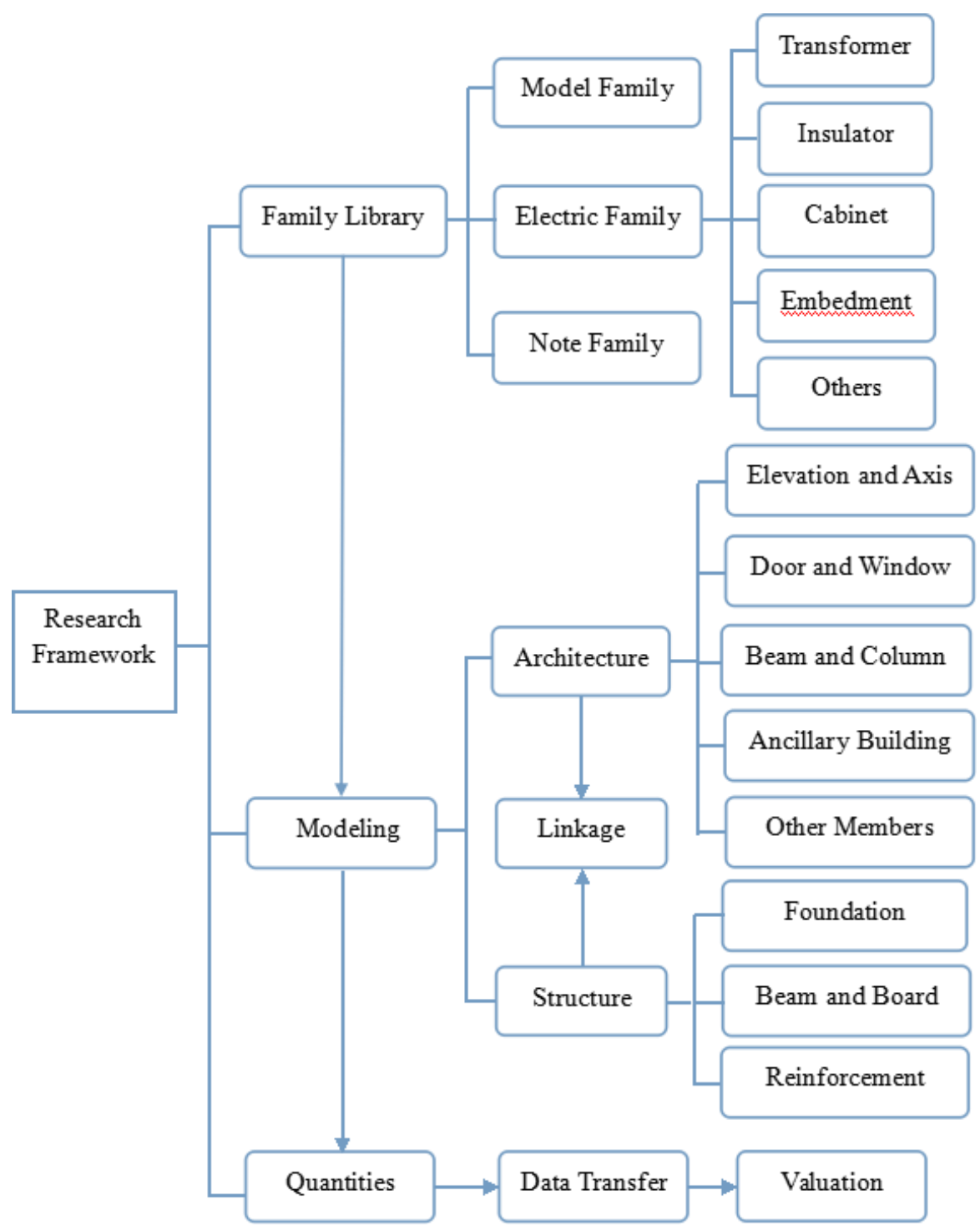

Figure 2. The Research Framework

\section{Project Description}

The substation project is located in north china, its floor space is $389.52 \mathrm{~m} 2$ and total construction area is $769.68 \mathrm{~m} 2$. The basic structure form is framework; and the main structure consist of two-story building, the first layer includes $10 \mathrm{kv}$ switch room, grounding transformer room, condenser room and living room, while the other layer includes $35 \mathrm{kv}$ switch room, equipment room, reference room, tool room and so on. Beyond that, the substation has ancillary buildings include pumping station, reservoir and accident oil pool. The objective picture see Figure 3. 


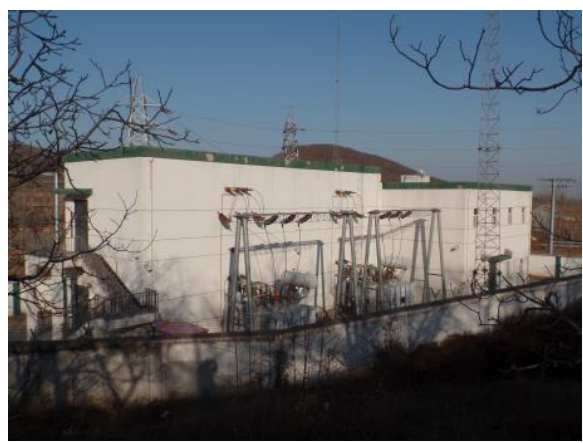

Figure 3. The Substation Physical Picture

\section{Family Library Construction}

In Revit software, the basic graphic unit such as wall, door and window is called metafile which is created by family. Family is a parametric component which includes other parameters of free regulation that controls metafile's material, size, location and other information [25]. Other than that, family is the basis and essence of Revit software, the more the parameter means the more the information we can obtain and the more the embody value of BIM technology [26]. There are five basic commands namely stretching, integration, rotation, lofting and lofting integration that can create all sorts of family files. And, through the information-integration and processing, we can build a family library that apply to power engineering cost [27].

\subsection{Information-Integration}

There are two ways to construct information framework. One is using less family and more family types to express component information, that is a family contains all stages and parties information. This way contains many family parameters and easy to cause confusion, but it can maximize the information utilization rate. Once loaded this framework into the project, the family can be added more detailed messages with the process of construction. When we need to extract information, just filter out demand parameters. The other is using many families to express different parties and stages, which is easy to model and the library framework is relatively simple [28].

The first kind of life-cycle family is much more better, from BIM characteristics and development, as it makes BIM becomes a framework that large platform set small platform and conforms to future trend. But, at the currant stage, the second kind of stage family is more convenient and more efficient, it can exist as a transitional form [29-[30].

\subsection{Information-Processing}

For different phases, different users and different needs, the way of information processing is also different, but the flow of it is the same (see Figure 4). 


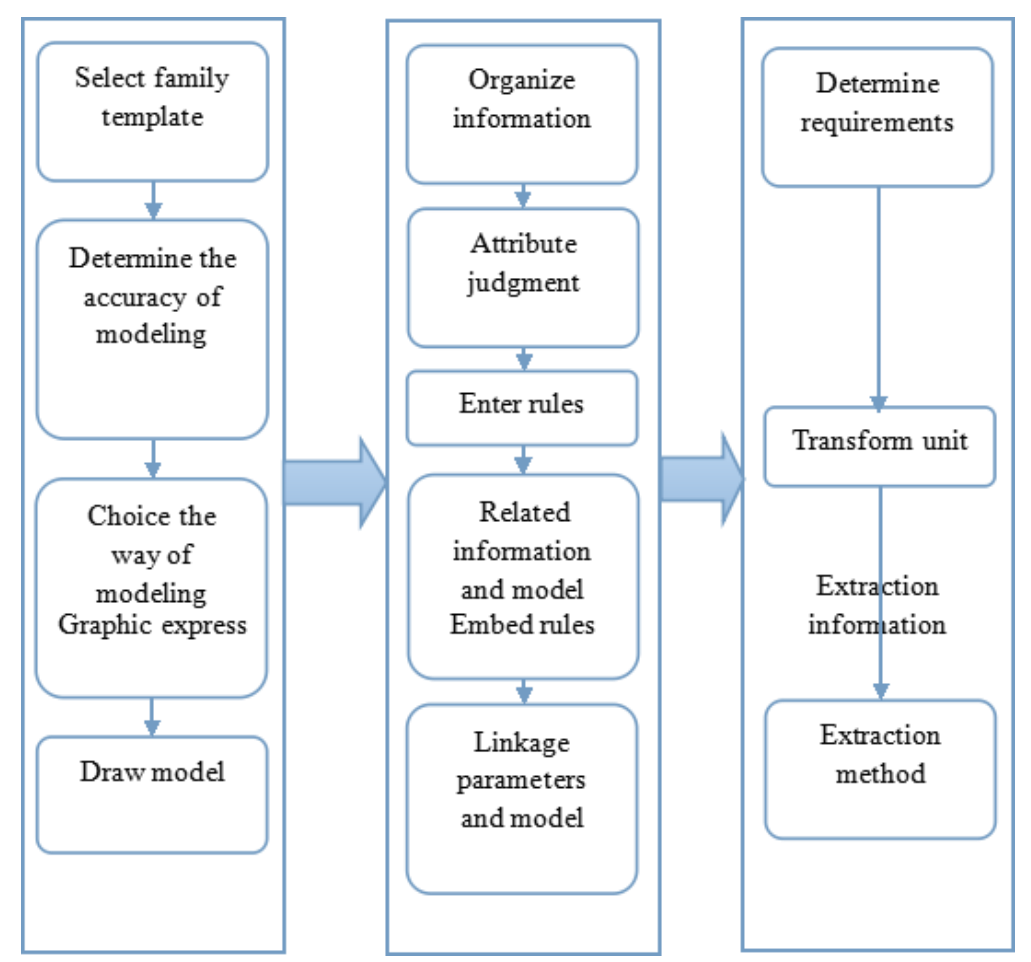

Figure 4. The Flow of Information Processing

According to the five basic commands and information technologies, the part of family library that created in this project see Table 2.

Table 2. Family Library

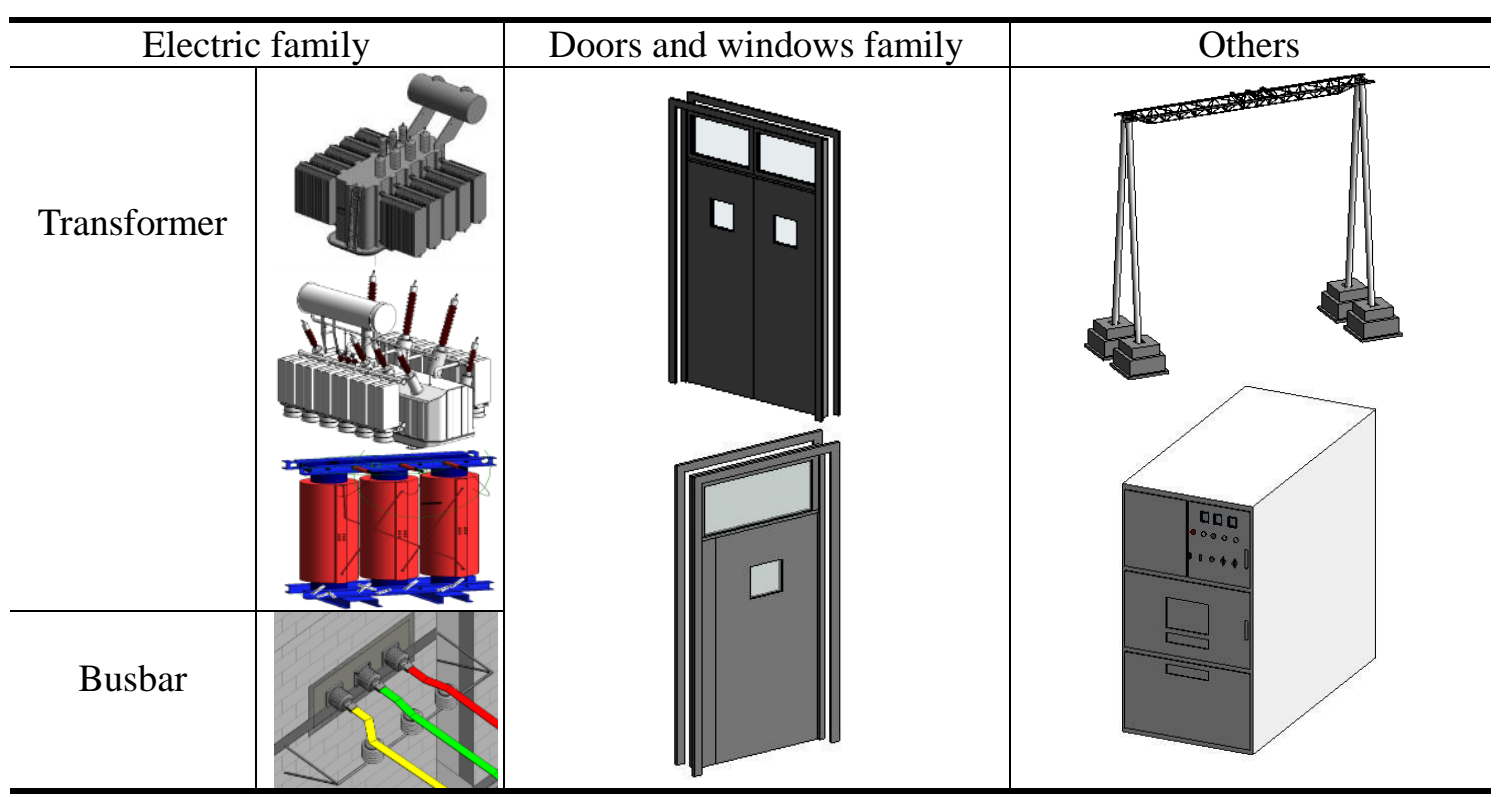




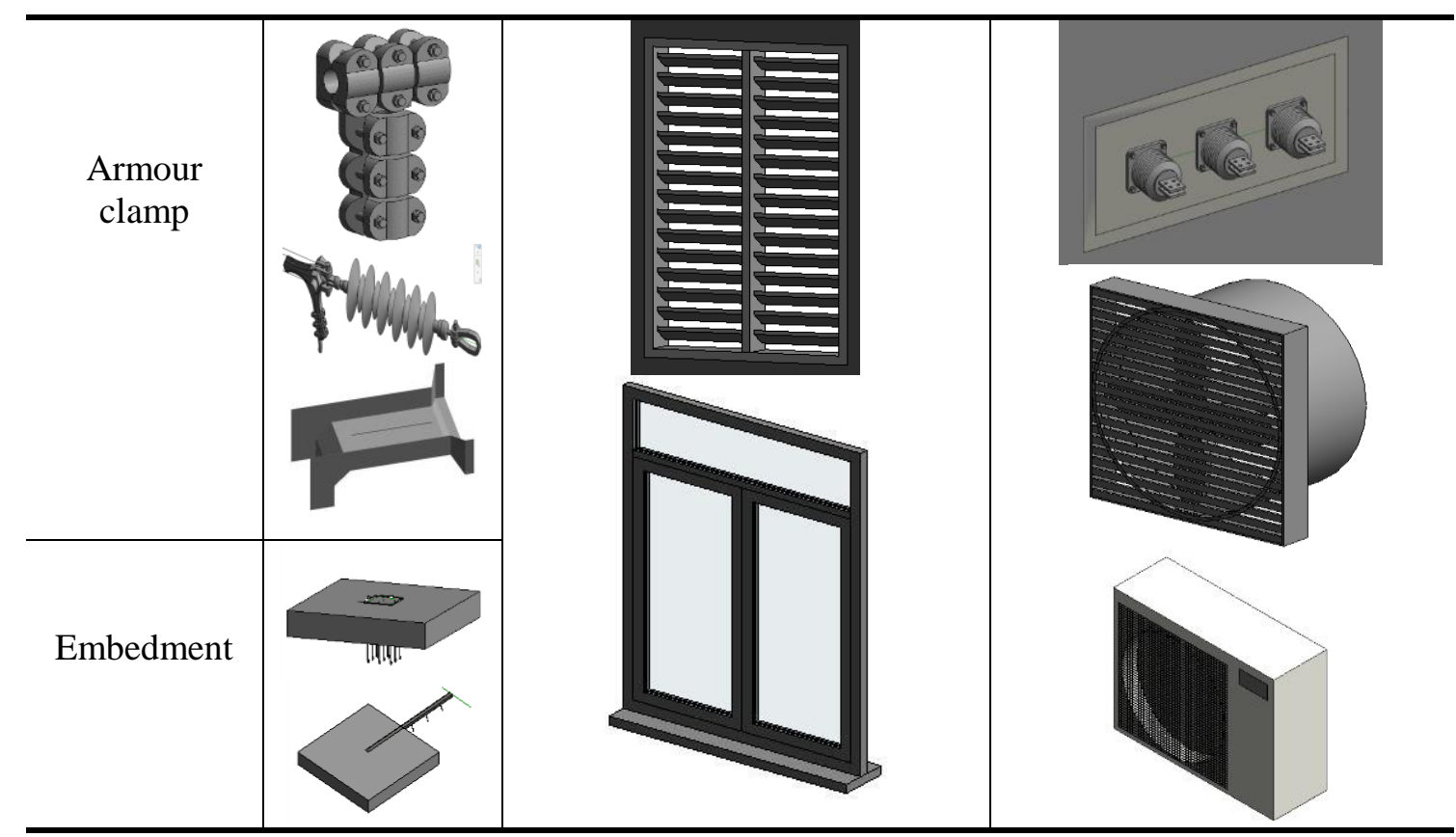

\section{Modeling Points}

\subsection{Elevation and Axis Net}

The first work of found BIM model is drawing the elevation and the axis net that are the foundation of architecture location. Their accuracy will directly influence the entire model' s success. When we draw elevation in elevation view, the software will automatically establish the plane view for each elevation and then draw the axis net in the plane view. If the software doesn' t create a plane view, the user can add the plane view manually in the view tab. We should ensure axis net pass through all elevations in each elevation view, else, the complete axis net cannot be displayed in a plane view which will affect latter part of the job.

In structure sample, the set of axis net needs higher requirement of accuracy, therefore we could use "copy/monitor" tool to copy architecture' s axis net accurately in order to facilitate modeling linkage.

\subsection{Main Building}

The main building is a substation building where the staffs live and work. At the bottom of first layer, switch room needs to lay the electrical cables, so we should design the cable trench beforehand (see Figure 5).

The cable trench is not only a major feature of substation, but also a difficulty in architecture design and quantity statistics. We can use wall and floor to build the cable trench, but the process of drawing it is a little bit tedious. Based on estimation norm, the cable trench's fee category is a complex ground and the fee is based on building axis size, we don' $t$ need to deduct the cave area and the rule of quantity statistics is the same as floors. But in the preliminary estimation norm, the cable trench is based on volume to count list, neither wall nor floor can calculate trench' s volume. The best solution is to use building volume that is a family type which doesn' t have any building property. After using volume modeling, we can calculate its volume and surface area directly in order to meet the demand. 


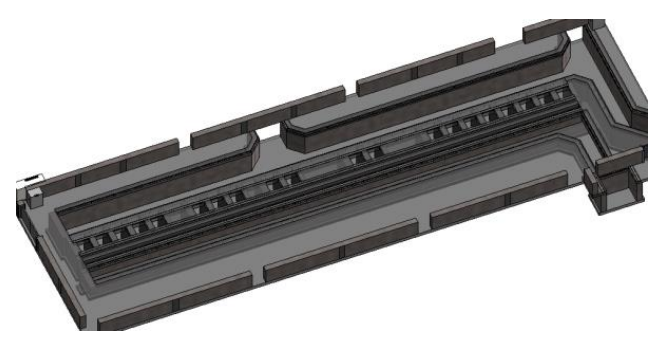

Figure 5. Cable Trench

\subsection{Main Structure}

The work of main structure is to configure the steel. We usually use Revit extension software which is a steel modeling plugin to achieve this work, and through inputting some numbers we can complete simply reinforcement work. Use the plugin to configure steel for foundation, beam, board and column at first, however, we will need to make some manual adjustment later in order to meet the design requirement due to some inaccuracy. Moreover, the biggest drawback of the plugin is it cannot configure the lateral steel; and for stairs and roof, we have to spend a lot of time to adjust the steel' s length, shape and angle manually, thus it greatly increased the complexity of modeling.

\subsection{Ancillary Buildings}

Ancillary buildings are drawn on different floor plane according to project requirements. The creation method of pumping station is similar to substation building, which usually starts from a simple process as drawing the wall and step by step. We can use "floor" tool to generate reservoir' $\mathrm{s}$ water that need to modify the properties. The accident oil pool is built by family manually, where on the top cover and the handle we should make a model group to facilitate their linkage change.

\section{Quantity Statistics}

Quota is an important basis for produce estimation norm, handle engineering settlement and carry out project claim and counterclaim. Correctly understanding and using quota has been even more important. The latest version of electric power quota (2013 edition) is a authority standard that includes estimation quota and preliminary estimation quota, it can regulate engineering investment and conduct construction cost estimation [31].

After creating the model, we can obtain the list, but some of them cannot be used directly as fee benchmark [32]. We found that for individual component, as long as it can accurately express in the model, the list can provide correct quantity that fits power quota; while, for wall, column and other concrete members, there are some errors in the list. Take a beam as example, the quantity is $3.56 \mathrm{~m} 3$ provided by the software. However, the actual quantity is $5.15 \mathrm{~m} 3$ by hand according to the quota rules. The error reaches $30.85 \%$ that has been far beyond the estimation norm margin.

\subsection{Door List}

In the estimation quota, the price of the door determined by its type, form and structure, the list provided all information and the door belongs to individual component, so we can directly use it. The door list see Figure 6. 


\begin{tabular}{|c|c|c|c|c|c|c|}
\hline \multicolumn{7}{|c|}{$<$ Door list $>$} \\
\hline & $B$ & C & D & $\mathrm{E}$ & $\mathrm{F}$ & G \\
\hline$\frac{\text { A }}{\text { Type }}$ & \multicolumn{2}{|c|}{ Size } & Tab & Total & Form & Structure \\
\hline & & & & & & \\
\hline $800 \times 2100 \mathrm{~mm}$ & 2100 & 800 & M854 & 1 & Double fan & Wooden door \\
\hline $1000 \times 2000 \mathrm{~mm}$ (B) & 2000 & 1000 & M849 & 4 & Singal fan & Fire door \\
\hline $1000 \times 2400 \mathrm{~mm}$ & 2400 & 1000 & M853 & 5 & Singal fan & Fire door \\
\hline $1000 \times 2400 \mathrm{~mm}$ & 2400 & 1000 & $M 857$ & 1 & Double fan & Wooden door \\
\hline $1000 \times 2700 \mathrm{~mm}$ (B) & 2700 & 1000 & M834 & 4 & Singal fan & Fire door \\
\hline $1200 \times 2700 \mathrm{~mm}$ & 2700 & 1200 & $M 843$ & 1 & Double fan & Wooden door \\
\hline $1800 \times 2500 \mathrm{~mm}(\mathrm{~B})$ & 2500 & 1800 & M858 & 1 & Singal fan & Fire door \\
\hline $1800 \times 2700 \mathrm{~mm}(\mathrm{~B})$ & 2700 & 1800 & WM1 & 2 & Singal fan & Fire door \\
\hline $1800 \times 3000 \mathrm{~mm}(\mathrm{~B})$ & 3000 & 1800 & M856 & 1 & Singal fan & Fire door \\
\hline
\end{tabular}

Figure 6. Door List

\subsection{Wall Quantity}

According to the estimation norm, wall's quantity calculation should meet the following rules: the length is determined by axis dimension; the height is from indoor floor elevation to parapet top elevation if building has parapet, otherwise, the height is from indoor floor elevation to cornice top elevation; the thickness is decided by the standard calculation table (see Table 3) [33].

Table 3. Calculation Table

\begin{tabular}{cccccccc}
\hline Brick type & $1 / 4$ brick & $1 / 2$ brick & $3 / 4$ brick & 1 brick & $3 / 2$ brick & 2 brick & $5 / 2$ brick \\
\hline Thickness & $53 \mathrm{~mm}$ & $115 \mathrm{~mm}$ & $180 \mathrm{~mm}$ & $240 \mathrm{~mm}$ & $365 \mathrm{~mm}$ & $490 \mathrm{~mm}$ & $615 \mathrm{~mm}$ \\
\hline
\end{tabular}

Revit software can provide area, volume, elevation and other information, we just need to extract volume data and the software will accurately calculate all walls' quantities and automatic summation. These quantities include error that need adjustment. The quantity statistics and error analysis see Table 4.

Table 4. The Quantity Comparison and Error Analysis

\begin{tabular}{cccc}
\hline Quota item & Model quantity & Manual quantity & Error \\
\hline Exterior wall & $161.18 \mathrm{~m}^{3}$ & $167.59 \mathrm{~m}^{3}$ & $3.8 \%$ \\
Interior wall & $75.02 \mathrm{~m}^{3}$ & $93.56 \mathrm{~m}^{3}$ & $19.82 \%$ \\
& In the quota, wall's quantity calculation don't deduct the volume of \\
Reason & $\begin{array}{l}\text { architecture column, structure beam and lintel, so model quantity is } \\
\text { smaller than manual quantity. }\end{array}$ \\
\hline
\end{tabular}

Other reinforced concrete members, such as beam, column and board, they are have different calculation rules. In the power quota, the overlap between beam (or column) and board counted as beam (or column), while it is counted as board in Revit' s own program [34]. In order to reduce the error between model quantity and manual quantity, we have three methods. One way is setting a coefficient for each quantity and get satisfactory approximate value. This way needs lots of data and keep trying and the process is very tedious. Another way is to familiarize the quota calculation rules in the early stage, and use it as the feed forward control standard in modeling. Then remove the quantities error in the design stage in order to get the correct quantities after modeling [35]. For example, appropriate adjustment in board' s boundary line and substitute overlap with beam, through this method we can get a modeling that conform to quota rules. The last way is to implement data transfer, the way is the most realistic approach that need not to intervene and change designer's work. 


\section{Data Transfer and Valuation}

As some quantities cannot be directly used, the problem that we face is how to achieve data transfer, there are three ways (see Table 5) [36-[37].

\section{Table 5. The Way of Data Transfer and Its Merits and Demerits}

\begin{tabular}{|c|c|}
\hline $\begin{array}{l}\text { Family information } \rightarrow \\
\text { Calculation software } \rightarrow \\
\text { Pricing software }\end{array}$ & $\begin{array}{l}\text { Merits:The existing calculation software and pricing software have } \\
\text { the same data interface format, they can realize seamless } \\
\text { connection. } \\
\text { Demerits: 1) Need to draw up various Revit export file interface } \\
\text { standard, such as floor, elevation system and origin position norm. } \\
\text { 2) Data interface isn't listed in the project plan, difficulty to } \\
\text { exploit and need to pour huge human and material resources. }\end{array}$ \\
\hline $\begin{array}{l}\text { Family information } \rightarrow \\
\text { Revit list } \rightarrow \text { Excel } \rightarrow \\
\text { Pricing software }\end{array}$ & $\begin{array}{l}\text { Merits: The feasibility and generality of the scheme are the } \\
\text { highest, we don't need to change the pricing software's data } \\
\text { interface, import data and calculate price is fast and easy. } \\
\text { Demerits: Operation process is very tedious, for modeling side we } \\
\text { need to formulate a set of rules or work out a plug-in that is a } \\
\text { enormous thing. }\end{array}$ \\
\hline $\begin{array}{l}\text { Family information } \rightarrow \\
\text { Revit list } \rightarrow \text { Pricing } \\
\text { software }\end{array}$ & $\begin{array}{l}\text { Merits: This is a sound scheme, for modeling side as long as } \\
\text { according to data interface that Glodon provides and export Revit } \\
\text { list correctly, and then import the list into the pricing software, we } \\
\text { are able to achieve valuation work. } \\
\text { Demerits: 1) The Glodon company need to development interface } \\
\text { rules that need a certain development cycle. } \\
\text { 2) To cast it in promotion terms, if just the Glodon developed the } \\
\text { pricing interface, others are also need to development interface } \\
\text { that caused repeat work. }\end{array}$ \\
\hline
\end{tabular}

We adopt the second method finally, turn the Revit list into Excel form and processing information then import it into pricing software.

The quantity excel connected to the pricing software that Glodon company provide, through material, stage and type fields free combination with each other to achieve quota items and excel header match exactly (see Figure 7), and complete items auto-format. The work flow of designer and cost engineer see Table 6.

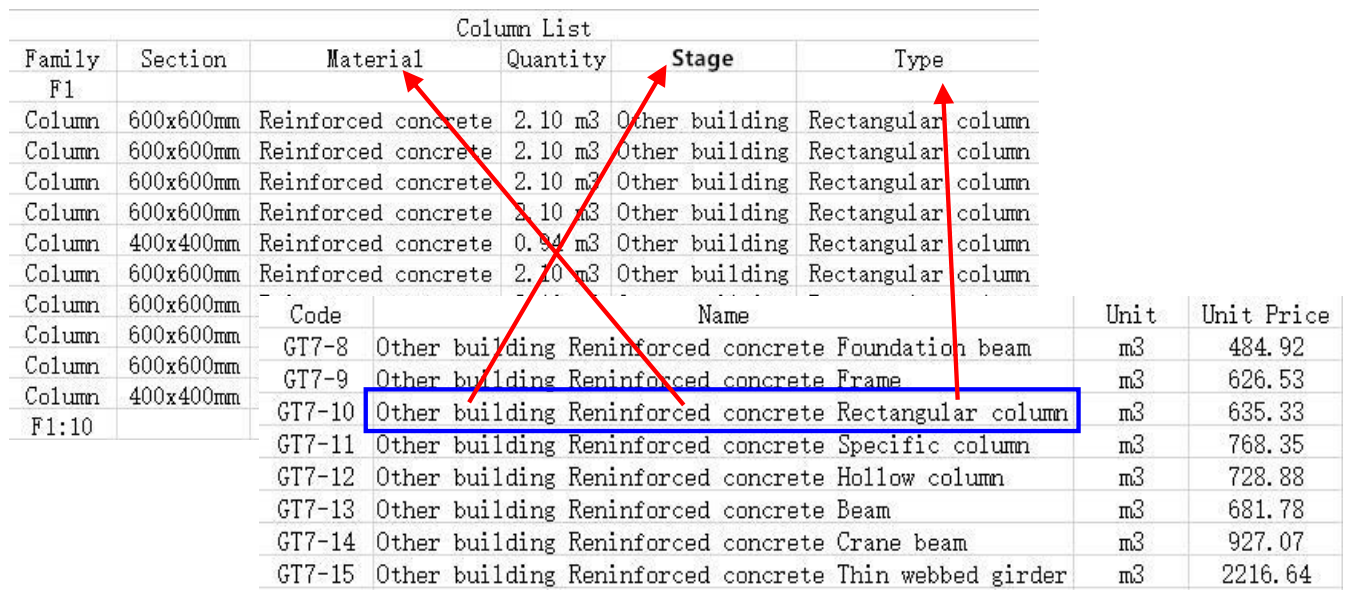

Figure 7. Match Item 
Table 6. Business Flow Chart

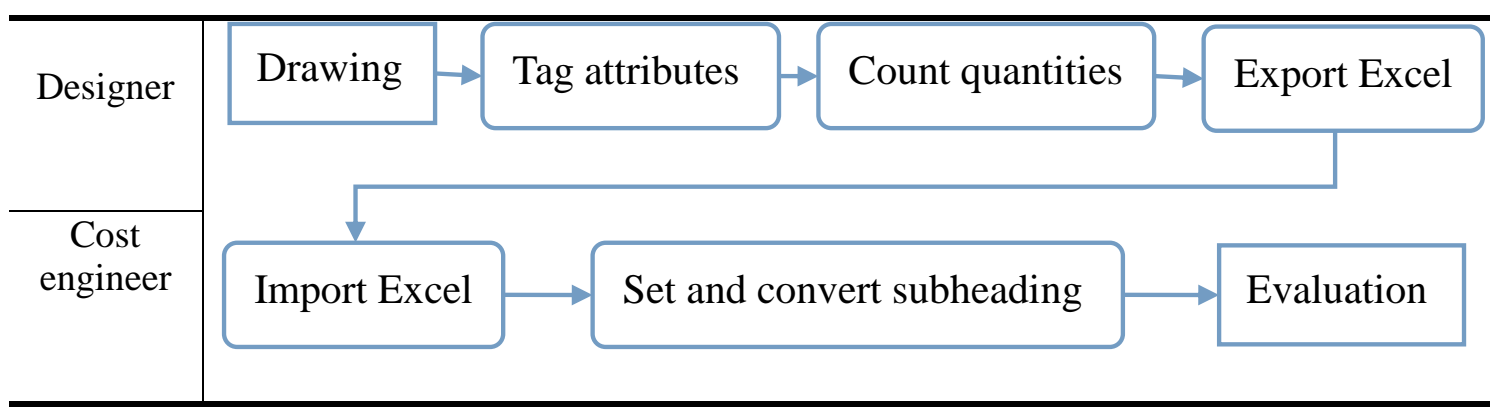

The scheme has the following advantages:

(1) We can regulate different roles' work without changing their work pattern, such as designer to classify components and accurately describe the classification attribute; Cost engineer apply the quota items according to the requirements.

(2) Through match items automatically with the keywords manually, the matching rate can reach $100 \%$.

Multiply quantity by unit price, we can get the substation's engineering cost, such as total project cost is RMB 22.63 million, construction cost is RMB 6.7 million, original equipment cost is RMB 10.72 million, installation fee is RMB 1.36 million, other expenses are RMB 3.85 million.

\section{Conclusion}

This paper present a case study where a 5D model is applied to a substation construction project, and BIM 5D technology can be used in the electric power construction industry has been confirmed. One of the unique contributions of this study is that we find the superiority of applying 5D model for the substation project, it includes: 1) collision detection and reduce rework, it saved RMB 1.3 million for the project cost; 2) virtual construction and work together, it helped that the construction work was completed three months in advance; 3 ) rapid calculation and lifting efficiency, it could cut labor costs and improve efficiency by about $70 \%$; 4 ) it will facilitate the life cycle management (see Figure 8), [38].

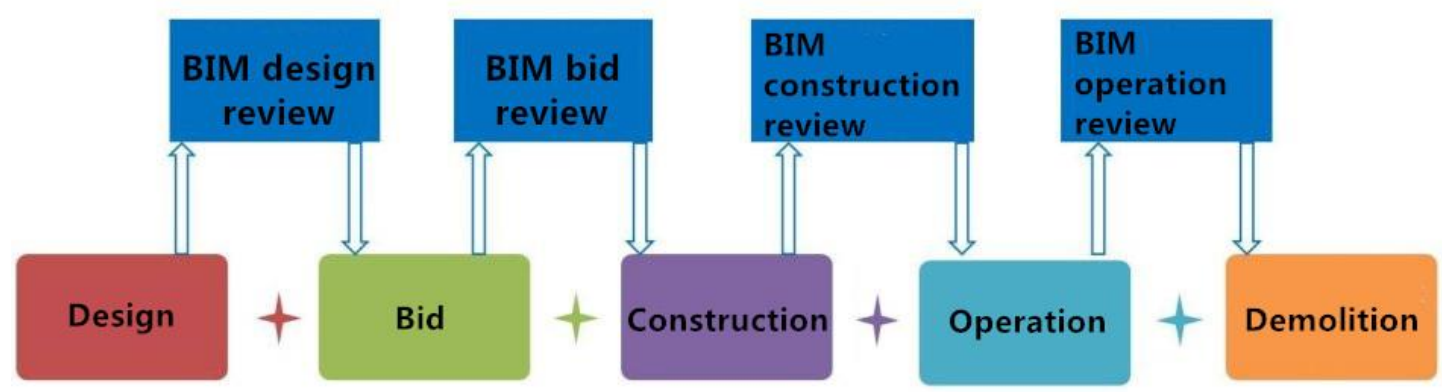

Figure 8. BIM Life Cycle Management

At present, many difficulties and problems are also remain in the power engineering cost, BIM can only solve these problems to some extent (see Table 7) [39]. 
Table 7. A Degree of Using BIM Technology To Solve Cost Problems

\begin{tabular}{|c|c|c|c|}
\hline Number & Problem & Apply BIM technology & Degree \\
\hline 1 & $\begin{array}{l}\text { Manual calculate quantity } \\
\text { that waste time and energy }\end{array}$ & $\begin{array}{l}\text { Automatic statistics and high } \\
\text { accuracy }\end{array}$ & 1 \\
\hline 2 & $\begin{array}{l}\text { Information can't flow } \\
\text { freely between the cost } \\
\text { engineer }\end{array}$ & $\begin{array}{l}\text { Provide a information share } \\
\text { platform and foster information } \\
\text { sharing }\end{array}$ & 1 \\
\hline 3 & Multiple valuation & Life cycle valuation & 2 \\
\hline 4 & $\begin{array}{l}\text { Work visa and engineering } \\
\text { change occur frequently }\end{array}$ & $\begin{array}{l}\text { Reduce engineering change and } \\
\text { shorten recount quantity time }\end{array}$ & 1 \\
\hline 5 & $\begin{array}{l}\text { Different dimensions' cost } \\
\text { need many times } \\
\text { computations }\end{array}$ & $\begin{array}{l}\text { Realized multi-dimension statistics } \\
\text { and helps to contrast }\end{array}$ & 1 \\
\hline 6 & $\begin{array}{l}\text { It is easy to lose historical } \\
\text { information and data are } \\
\text { difficult to maintain }\end{array}$ & $\begin{array}{l}\text { Data have complete continuity and } \\
\text { as a reference for future projects }\end{array}$ & 2 \\
\hline 7 & $\begin{array}{l}\text { Cost information break } \\
\text { away from market }\end{array}$ & $\begin{array}{l}\text { Due to the instability of the market, } \\
\text { can not be solved at present }\end{array}$ & 3 \\
\hline
\end{tabular}

Note: 1 - All solved; 2 - Partly solved; 3 - Can not be solved.

Power construction project involves many professionals and different types of buildings and structures, in order to realize the application of BIM technology in the power engineering cost also needs more attempt and exploration.

\section{Future Work}

Since power construction project is unlike civil engineering, BIM technology faces three major barriers in the power industry. The first is lack of appropriate standards. In 2007, National Institute of Building Sciences released USA's national BIM standard; in 2009, UK released AEC (UK) BIM Standard; in 2010, Korea released BIM application manual; in 2012, Singapore released Singapore BIM Guide. More and more countries have set BIM national standard, Chinese government should step up the pace [40]. The second is lack of software interface. In order to adapt the local cost policy, Gloden company and Autodesk company have reached strategic cooperation relationship, the Revit software will add a interface that is distinguished by Gloden cost software in the near future. It will make cost work easier and promote the extension of BIM technology. The third is lack of BIM talent. A lot of BIM researchers are short of theoretical basis and just focus on software, they are only technicians rather than BIM talents, personnel training mode with a strong utilitarianism that need to be improved [41].

The obstacles at current stage are priorities for our future work. With the coming of engineering information age, the power cost mode based on BIM technology is inevitable, it can not only save labor and enhance efficiency, but also cost savings and bring benefits. It should be obvious to everybody that BIM 5D technology has a long way to go in china electric power industry.

\section{Acknowledgements}

The research work presented in this paper was initiated by China Electricity Council, East China Electric Power Design Institute and North China Electric Power University. Acknowledgment also goes to Glodon company which participated in and co-studied the research work presented in this paper and contributed time of their staff members and 
experts to the research and developmental work that has been described in this paper.

\section{References}

[1] National Institute of Building Sciences, "National Building Information Modeling Standard", United States, (2007).

[2] J. WANG, "Application study of BIM concept and BIM software in the construction project", Southwest Jiaotong University, Chengdu, (2011).

[3] W. LIN, J. LU, L. CHEN, M.WU and X. ZHANG, "The application of BIM in construction organization design in the Xiaonanhai hydropower station", Hydropower and New Energy, vol. 1, no. 6, (2013), pp. 32-37.

[4] H. SHEN, "Substation modeling and quantity statistical based on BIM technology", North China Electric Power University, Beijing, (2014).

[5] C. Qi and H. Su, "Discussion on several problems about quantity calculation software based on Revit", Computer Engineering and Design, vol. 3, no. 14, (2008), pp. 60-62.

[6] Z. Lou, "Study on the system model of building cost budget software based on BIM technology", Tsinghua University, Beijing, (2009).

[7] Z. Ma and X. Zhang, "The framework design of engineering budget software based on BIM technology", 15rd National Conference on Engineering Design and Computer Application, (2010) September 16-17, pp. 313-318.

[8] X. Zhang, "The development of engineering budget software based on BIM technology", Tsinghua University, Beijing, (2011).

[9] S. Zhang, "Application of BIM in the engineering cost management", Building Economy, vol. 8, no. 2, (2012), pp. 20-24.

[10] J.Li and H.Fang, "The whole process of project cost management based on BIM", Building Economy, vol. 3, no. 9, (2012), pp. 96-100.

[11] Y. Wang and Y. Li, "Research on the construction of life cycle cost management information system based on BIM technology", Journal of Engineering Management, vol. 26, no. 2, (2012), pp. 22-27.

[12] X. Chai, "Study on the construction and implementation of engineering dynamic information database based on BIM technology", Technology and Management, vol. 15, no. 3, (2013), pp. 67-70.

[13] J. Laiserin, "Comparing Pommes and Naranjas", Arichitectural Creation, (2002).

[14] K. Lee, S. Chinm and J. Kim, "A core system for design information management using industry foundation classes", Computer-Aided Civil and Infrastructure Engineering, vol. 18, no. 5, (2003), pp. 286-298.

[15] F. Sherl, "Providing Cost and Constructability Feedback to Designers", Construction Research Congress, vol. 19, no. 20, (2003), pp. 1-8.

[16] V. R. Kamat, "Evaluation of standard product models for supporting automated erection of structural steelwork", Automation in Construction, vol. 16, no. 6, (2007), pp. 232-265.

[17] A. M.Tanyer, "Formalism and Mechanism Needed to Maintain Cost Estimates based on an IFC Product Mode", 8rd International Conference on Computing in Civil and Building Engineering, (2000) December 24-25, pp. 1-9.

[18] Bazjanacz, “Applying Information Modeling to Buildings", Virtual Building Environments, vol. 10, no. 19, (2006), pp. 185-192.

[19] S. Staub-French, A. Russell, and N. Tran, "Linear Scheduling and 4D Visualization", Journal of Computing in Civil Engineering, vol. 5, no. 6, (2008), pp. 192-205.

[20] Succar, "Building information modeling framework: A research and delivery foundation for industry stackeholders", Automation in Construction, vol. 18, no. 9, (2009), pp. 357-375.

[21] K. Kim, G. Kim, K. Kim, Y. Lee and J. Kim, "Real-time progress management system for steel structure construction", Journal of Asian Architecture and Building Engineering, vol. 8, no. 1, (2009), pp. 111-118.

[22] Q. Li, "Research on document management system under the BIM environment", Dalian University of Technology, Dalian, (2011).

[23] G. Lee, "D3 City project-Economic impact of BIM-assisted design validation", Automation in Construction, vol. 10, no. 22, (2012), pp. 577-586.

[24] D.Bryde, "The project benefits of Building Information Modeling (BIM)", International Journal of Project Management, vol. 29, no. 45, (2013), pp. 1-10.

[25] G. HE, "BIM and BIM related software", Building and Civil Engineering Information Technology, vol. 2, no. 4, (2010), pp. 110-117.

[26] J. WU, "The localization strategy of research on Building Information Modeling (BIM)", Tsinghau University, Beijing, (2011).

[27] D.Bryde, M.Broquetas and J. M. Volm, "The project benefits of Building Information Modelling (BIM)", International Journal of Project Management, vol. 31, no. 7, (2013), pp. 971-980.

[28] A. Porwal and K. N. Hewage, "Building Information Modeling (BIM) partnering framework for public construction projects", Automation in Construction, vol. 31, no. 20, (2013), pp. 204-214.

[29] L. Chen and H.Luo, "A BIM-based construction quality management model and its applications", 
Automation in Construction, vol. 46, no. 30, (2014), pp. 64-73.

[30] P.YANG, "Application research of Building Information Modeling”, HeFei University of Technology, Hefei, (2013).

[31] X. Wei, "Discussion on electric power quota application notes", Science and Technology for Development, vol. 20, no. 11, (2011), pp. 35-37.

[32] H. E. Goldberg, "Design date for construction-AEC industry progresses by evaluation construction costs and project management using BIM", AEC from the Ground Up, vol. 34, no. 90, (2006), pp. 45-47.

[33] Y. YAN, "Research of construction budget management based on BIM", Huazhong University of Science and Technology, Wuhan, (2013).

[34] Xi. XU and F. ZHOU, "Analysis on BIM technology to boost cost management reform", Engineering Economy, vol. 9, no. 12, (2014), pp. 15-17.

[35] P.ZHOU, "BIM technology bring out cost consultation industry innovation", Project Management, vol. 21, no. 6, (2014), pp. 61-63.

[36] B.YANG, "The whole process of cost management solution based on BIM", City and House, vol. 11, no. 6, (2014), pp. 101-105.

[37] Se. MENG, X. LIU and S.ZHANG, “Analysis on BIM cost management”, Engineering Construction, vol. 61, no. 5, (2012), pp. 109-111.

[38] Z.Zhang, H.Jiang and P. Fu, "How to see the input and output of BIM value", Construction Enterprise Management, vol. 50, no. 12, (2013), pp. 40-41.

[39] Y. Xu, "Research on BIM application and road-map in construction cost of electric power engineering", North China Electric Power University, Beijing, (2015).

[40] Y. Li, "Domestic and international BIM standards and technology policy", Information of China Construction, vol. 32, no. 20, (2012), pp. 14-17.

[41] BIMcn, "The existing problems of BIM technology promotion in our country", http://www.bimcn.org/cjwt/201412162440.html, (2014).

\section{Authors}
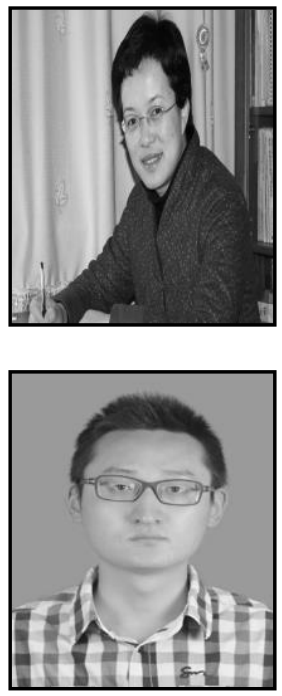

Rui Liu, Ph. D. and associate professor. Her research interests include project management, green building and BIM.

Xiaoqiang Hu, Master. His research interests include project management, BIM and construction cost. 